Cad.Est.Ling., Campinas, (45):33-41, Jul./Dez. 2003

\title{
CONSIDERAÇÕES ACERCA DA RELAÇÃO LINGUAGEM E COGNIÇÃO NA CIÊNCIA COGNITIVA
}

\author{
VIVIAN FERREIRA DIAS \\ (UNESP/Marília)
}

\begin{abstract}
The present study searches to investigate the notion of language as well linguistic aspects privileged by Fodor (important representative of Cognitive Science) as far as establishment of relationships between cognition and language is concerned. This investigation will be based on representative material of author's studies focusing, mainly, on dichotomy natural language $\mathrm{X}$ language of thought.
\end{abstract}

INTRODUÇÃO (um breve histórico)

Entendemos que a Ciência Cognitiva (doravante CC) é um campo do conhecimento relativamente novo; portanto, talvez ainda desconhecido para alguns. Desse modo, esta apresentação irá contemplar alguns aspectos do percurso da CC, as influências recebidas por esse campo do saber, bem como as origens de nosso interesse pelo estudo a que nos propomos realizar.

Segundo Gardner (1996), o primeiro indício de surgimento mais efetivo da Ciência Cognitiva ocorreu no final da década de quarenta, mais especificamente no Simpósio Hixon, que reuniu profissionais de áreas diversas (psicólogos, lingüistas, lógicos, engenheiros, entre outros). Nesse simpósio, algumas comparações foram realizadas entre cérebro e máquina. Resumidamente, a partir desse evento, várias disciplinas se uniram no sentido de desvendar o antigo enigma da mente humana, mas parece haver um consenso entre os historiadores da CC, segundo Gardner, que somente em 1956 é que esse novo campo do saber foi reconhecido. Os domínios do saber que estavam no âmbito da CC passaram a propor a utilização de processos computacionais para tentar simular o que ocorre na mente ou no cérebro quando em atividade de conhecimento. Como a linguagem é entendida como uma dessas atividades, a Lingüística também participa do quadro interdisciplinar da CC.

Como já foi dito, dentre as habilidades humanas que a CC se dispôs a estudar, encontrava-se a linguagem. Um dos aspectos considerados na simulação e/ou compreensão da cognição humana era (e ainda é) o lingüístico. Pressupõe-se, pois, que os estudiosos da CC devam atribuir algum grau de relação entre linguagem e cognição, algum ponto de contato entre ambas, em sua tarefa de compreender os comportamentos humanos ditos inteligentes.

Na história da criação da Ciência Cognitiva, ou melhor, de seu estabelecimento enquanto ciência, visualizamos diferentes idéias referentes à relação entre linguagem e cognição.

Tendo em vista que as primeiras décadas do século $\mathrm{XX}$ foram fortemente influenciadas pelo pensamento behaviorista, seus seguidores, assim sendo, pouco se preocupavam com a natureza da linguagem. Esses cientistas, centrados especialmente no comportamento humano, relutavam em investigar a linguagem humana, alegando ser essa complexa, entendida enquanto uma forma de pensamento relativamente invisível (GARDNER, 1996).

No contexto do nascimento e estruturação da CC, Chomsky, ao contrário dos behavioristas, acreditava que a observação da organização da linguagem seria a melhor maneira de conceitualizar 
e estudar processos de pensamento, na medida em que a linguagem, a seu ver, possui todas as precisões formais da matemática. Como tal definição facilitava a modelagem da linguagem em termos computacionais, as idéias de Chomsky passaram a ter importância crucial nos estudos da CC.

É interessante notar que, de modo geral, a complexidade da linguagem sempre esteve presente em muitos argumentos contrários à CC. Quando se combatiam os avanços da Inteligência Artificial, o apelo sempre se dirigia aos aspectos lingüísticos não contemplados e/ou considerados. Exemplo desses combates é o trabalho de Searle (1980), no qual o autor defende que as máquinas não apresentam semântica e não possuem o significado daquilo que manipulam; portanto, segundo Searle, não poderão jamais "pensar".

Algumas tentativas de se criarem programas que "manipulam" a linguagem ainda são realizadas atualmente. Contudo, limitações continuam a ser apontadas, talvez decorrentes dos aspectos lingüísticos privilegiados na tentativa de estabelecer a relação entre cognição e linguagem.

Uma vez que o funcionamento da linguagem ainda se apresenta como um desafio à $\mathrm{CC}$, entendemos ser interessante apresentar o que se "diz" sobre a linguagem no interior da CC, quando do estabelecimento de relações entre cognição e linguagem. Em outras palavras, pretendemos identificar como a linguagem é vista pela $\mathrm{CC}$, ou seja, a maneira pela qual é concebida e o que se privilegia dela.

Entretanto, apontar as concepções de linguagem apresentadas pela totalidade dos trabalhos pertencentes à CC parece muito pretensioso. Sendo assim, como Fodor vem despontando como o autor mais representativo da questão que nos interessa, selecionamos para o momento sua importante obra The language of thought, de 1975. Acreditamos, pois, que as idéias veiculadas por meio da obra supracitada pode nos fornecer uma visão não apenas das concepções de linguagem, como ainda dos aspectos lingüísticos privilegiados quando do estabelecimento dessa relação no quadro da CC.

Em suma, de acordo com o que já adiantamos, com a presente explanação buscamos fornecer uma visão geral das idéias de Fodor acerca da linguagem. Acima de tudo, pretendemos apontar quais os aspectos que o autor prioriza quando apresenta sua concepção de linguagem e as informações lingüísticas atreladas a ela. Contudo, salientemos que, considerando a diversidade de informações lingüísticas apresentadas por Fodor, iremos focalizar mais precisamente os dois tipos de linguagem que o autor defende, a saber: linguagem natural ou pública e linguagem do pensamento ou privada (o que será explicitado logo mais).

A partir dessa delimitação, tendo em mãos dados referentes às concepções de linguagem apresentadas por Fodor, quando este autor relaciona linguagem e cognição, iremos confrontá-los com os pressupostos teóricos provenientes do campo de estudos em neurolingüística. Tal confronto, longe de ser apenas uma crítica ao pensamento fodoriano, pretende mostrar o que o autor pode estar negligenciando da linguagem quando apresenta suas concepções a respeito desse fenômeno. Dito de outra forma, por meio do "encontro" desses dados com os pressupostos de uma teoria lingüística que considera, além da organização formal dos elementos lingüísticos, fatores de natureza sociocultural e subjetiva envolvidos no uso da linguagem, queremos apontar quais são as informações lingüísticas que Fodor deixa "escapar" do seu "discurso" sobre a linguagem, ou melhor, "as linguagens", quando da tentativa de sua compreensão ou de sua simulação artificial.

Se, por um lado, esse percurso de análise possa parecer óbvio e bastante simplista aos olhos de um lingüista, por outro, para os estudiosos do campo da Ciência Cognitiva (CC), tais esclarecimentos, possivelmente, serão muito proveitosos. A necessidade de uma melhor compreensão dos aspectos lingüísticos, bem como dos pressupostos teóricos das diversas correntes em Lingüística, é uma necessidade urgente dos estudos em CC, especialmente daqueles que se voltam para a compreensão/ simulação da linguagem. Julgamos, ainda, ser extremamente importante apontar as influências lingüísticas que os estudos no interior da CC sofrem (que não apenas as inatistas, como vem sendo 
enfatizado), além de novas tendências que vislumbramos no cenário da Lingüística (e que podem melhor orientar os estudos e a simulação da linguagem nos domínios da CC).

\section{O AUTOR (Jerry Alan Fodor)}

Fodor pode ser localizado na corrente mais tradicional da CC, especificamente no seu ramo denominado Inteligência Artificial, ramo da informática que simula diversos fenômenos pelo computador, tal como o raciocínio, a demonstração de teoremas, a aprendizagem, a percepção (definição de Ganascia, 1996). A principal característica dos estudos nessa área é a de possuir um certo tom radical, que acaba por reduzir as habilidades cognitivas a fórmulas matemáticas, desconsiderando seus aspectos de ordem social, ambiental ou subjetiva.

Fodor está filiado à tradição internalista quando pensa nas computações (linguagem do pensamento, veículo que carrega as operações cognitivas). Foi o primeiro aluno de Putnam, tendo iniciado, como ele, nos anos 60, uma defesa do funcionalismo ${ }^{1}$, buscando compreender a mente sob a forma de um sistema computacional. Uma década mais tarde - em 1975, mais precisamente -, Fodor publicou The language of thought, passando a unir a proposta funcionalista a uma linguagem de pensamento.

A corrente computacional defendida por Fodor parte da idéia de que os estados mentais possuem relações causais entre si e respostas comportamentais. Como no behaviorismo, há aqui impulsos sensoriais que geram respostas comportamentais. Só que, inseridas neste processo, estão as relações mentais, que se dariam sob a forma de inputs e outputs. Ou seja, receber um input estando em um determinado estado mental, teria como conseqüência um output e o surgimento de outro estado mental.

Aqui, Fodor reafirma seu funcionalismo, definindo os processos mentais como sendo processos sintáticos. Todavia, disto não se segue que sejam igualmente sintáticas as leis psicológicas; estas seriam intencionais. São sintáticos os mecanismos através dos quais estas leis são implementadas. Desse modo, no projeto de causalidade mental, processos mentais sintáticos implementariam leis psicológicas, intencionais, que, quando aplicadas, poderiam causar uma resposta comportamental. A teoria da naturalização da intencionalidade (que, no interior dessa proposta, admite a presença de leis intencionais tais como crenças e desejos) é desenvolvida e percebida como necessidade por Fodor. O autor alia-se, desse modo, ao projeto naturalista do behaviorismo, adicionando relações causais entre estados mentais, o que resulta em uma causalidade mental efetiva.

Fodor tem sido considerado como o "pai do representacionismo", por sua defesa de que existem representações internas e de que não é possível pensar a linguagem desvinculada dessas representações. Para Fodor, os programas computacionais tendem ao fracasso, uma vez que não levam em conta as representações, ou, em outras palavras, o registro interno das experiências, das informações e conhecimentos do sujeito, fato que, para o autor, está claramente presente na linguagem (cf. FODOR, 2000).

\section{CIÊNCIA COGNITIVA: DUAS LINGUAGENS}

Para Fodor, as teorias computacionais pressupõem a existência e a exploração de um sistema de representações de alguma complexidade, no qual os processos mentais seriam veiculados. Desse

\footnotetext{
${ }^{1}$ Corrente de pensamento que entende que estados mentais são idênticos a processos mentais. Não importaria a constituição física desses eventos, mas o desempenho de suas funções.
} 
modo, segundo o autor, pode-se dizer que, para se usar o modelo computacional, seria necessário acessar um sistema de representação de considerável riqueza. Esse sistema é identificado como a linguagem do pensamento, já que essa seria, de acordo com Fodor, uma pré-condição para qualquer tipo de teoria séria na Psicologia Cognitiva.

$\mathrm{Na}$ perspectiva de Fodor, portanto, os processos cognitivos seriam entendidos como computacionais, pressupondo, dessa forma, um sistema representacional. Dessa maneira, para um organismo representar, independentemente do vocabulário ou da sintaxe, faz-se necessário o uso de um sistema representacional, da linguagem do pensamento.

Logo, para que haja representação, necessita-se de uma linguagem, visto que, de acordo com Fodor, não haveria nenhuma representação interna sem uma linguagem interna. Segundo o autor, uma linguagem teria que ter um acesso prévio a algum sistema representacional em que tais propriedades pudessem ser expressas. Embora seja diferente de uma língua natural, esse sistema representacional teria que ser capaz de expressar os predicados de uma língua natural e suas propriedades semânticas. Aliás, é dada tanta importância à representação no pensamento de Fodor que, para o autor, sem representação não haveria computação e sem computação não haveria modelo.

No entanto, embora a computação pressuponha uma linguagem representacional isso não significa que esta tenha que ser uma linguagem que funcione, em seus termos, como veículo de comunicação, ou seja, como uma linguagem natural. Desse modo, identificamos que a linguagem requerida pela computação seria a que Fodor denomina como linguagem privada ou do pensamento.

Como pudemos perceber, e de acordo com o que já adiantamos, há informações de diversas naturezas quando Fodor volta sua atenção para a linguagem. No entanto, por acreditarmos ser esse o melhor caminho, nossa atenção se voltará especialmente para a dicotomia que o autor realiza quando apresenta sua concepção de linguagem. Em outras palavras, para Fodor, existiria dois tipos de linguagem (como já citamos): uma denominada linguagem privada ou do pensamento, de caráter inato, e a outra chamada de linguagem pública ou natural, sendo esta aprendida. Fodor postula a existência desses dois tipos de linguagem estabelecendo algumas diferenças entre ambos, além das já citadas.

Podemos destacar, dentre essas diferenças, a própria função que cada um dos tipos de linguagem exerceria, segundo o autor. A linguagem privada ou do pensamento serviria com um meio para as computações básicas dos processos cognitivos, ou melhor, como um suporte para o pensamento. A linguagem pública ou natural, por sua vez, funcionaria como um veículo de comunicação entre falantes e ouvintes: 'Inglês para falantes de Inglês, Francês para falantes de Francês e Hindu para falantes de Hindu” (p. 56). Abre-se espaço aqui para salientar que Fodor, ainda que de forma implícita, baseia-se em uma visão de que a linguagem (a que ele denomina como pública) não passaria de um mero meio de comunicação, fato que nos remete a Jakobson e que é bastante criticado pelos estudos de orientação discursiva.

Posto dessa maneira, podemos dizer que a noção que Fodor apresenta, principalmente em relação à linguagem pública, muito se aproxima da idéia de código. $\mathrm{O}$ autor a concebe como veículo, um sistema de convenções para a expressão de intenções comunicativas. Vê-se, nessa perspectiva, concordâncias entre Fodor e idéias de Saussure e de estudiosos que podem ser remetidos ao pensamento estruturalista, no que se refere à visão da língua como uma organização interna de elementos tal como Saussure (1995) estabelece: ... a língua... é ao mesmo tempo um produto social e um conjunto de convenções necessárias, adotadas pelos membros da sociedade, de modo a permitir o exercício da linguagem nos indivíduos. (p.17). ${ }^{2}$

Por outro lado, Fodor dá especial ênfase ao papel que a linguagem do pensamento exerceria no comportamento e nos processos cognitivos. Isto porque, para o autor, esse tipo de linguagem

\footnotetext{
${ }^{2}$ Esta e as demais traduções que se verificarão neste texto são de nossa responsabilidade.
} 
serviria para conduzir as computações que fundamentam os comportamentos e para veicular os processos cognitivos. Além disso, como já mencionamos, quando Fodor discorre sobre o que considera como linguagem privada, ele parte da premissa de que, em particular, não há nenhuma representação interna sem uma linguagem interna. Ele define esta última, em suma, como o meio para as computações básicas dos processos cognitivos. Como se pode observar em Fodor, linguagem, em ambos os sentidos, seria meio: (a) de comunicação (no sentido de pública); (b) de computação de processos cognitivos (no sentido de privada).

Ainda fazendo referência à linguagem do pensamento, Fodor defende que o predicado parte de uma linguagem interna, visto que, para o autor, ninguém aprenderia L (a saber, linguagem natural) a menos que soubesse uma linguagem diferente de L (ou seja, dessa linguagem natural). Todavia, a linguagem interna deveria ser rica o suficiente para expressar as extensões dos predicados de L. Fodor chega a admitir que "há algum sentido em que ter uma linguagem possa talvez permitir o pensar dos pensamentos, pensamentos que apenas alguém que fala pode pensar" (p. 84-5). Em outras palavras, a linguagem natural mobilizaria outra parte, já que a linguagem pública seria, para ele, uma espécie de pré-requisito para alguns tipos de pensamento. Mas é nesse sentido talvez mais específico que Fodor chega a admitir ser a linguagem pública a base desse processo.

Fodor vai ainda mais longe nessa questão ao apresentar o argumento de que a linguagem natural não seria apenas um meio pelo qual expressamos nossos pensamentos, mas, na verdade, um meio pelo qual pensamos. Entretanto, acreditamos que, ao fazer essa afirmação, Fodor já pressuporia a tradução da linguagem natural em linguagem privada ou do pensamento (para a partir de então servir como um veículo do pensamento). Isto porque, de acordo com o autor, a linguagem natural seria convertida em linguagem do pensamento e, nessa conversão, as características universais da linguagem passariam a compor os aspectos da representação da língua nativa.

Aliás, nossa conclusão parece certa, uma vez que Fodor acaba por, de certo modo, negar o argumento acima, a saber, o de que a linguagem pública ou natural seria o meio pelo qual pensamos. $\mathrm{O}$ autor o problematiza na medida em que, para ele, haveria organismos não verbais que pensam. Contudo, para Fodor, os sistemas representacionais dos organismos pré-verbais e infra-humanos não podem ser linguagens naturais (é por esse motivo que dissemos acima que essa linguagem já seria convertida em linguagem do pensamento). A respeito disso, segundo Fodor:

não há nenhuma razão para supor que nossa Psicologia aplica-se apenas a organismos que falam. Se decidirmos por tal aplicação restrita não teremos nenhum modelo para aprendizagem, escolha e percepção em populações diferentes dos seres humanos fluentes. Por outro lado, utilizar linguagem natural para trabalhar com organismos que não falam torna-se restrito. (p.62).

Retomando as diferenças entre linguagem pública (ou natural) e linguagem privada (ou do pensamento), como já salientamos, a primeira seria aprendida, enquanto a segunda seria inata. Fodor justifica sua diferenciação argumentando que a linguagem natural seria baseada na formação e na confirmação de hipóteses. Para o autor, não haveria outra noção de como qualquer conceito seria aprendido, exceto pelo processo de formação e confirmação de hipóteses. Este processo ocorreria na experiência; logo, a linguagem pública seria aprendida. Para chegar a tal conclusão, Fodor apoia-se em Augustine e considera que a visão deste último autor pode ser um pré-requisito para qualquer tentativa séria de compreender como as línguas naturais são aprendidas.

Augustine descreve a aprendizagem de línguas humanas como se a criança viesse a um país estranho e não compreendesse a língua do país, isto é, como se já tivesse uma língua, mas apenas essa. Ou ainda, como se a criança pudesse já pensar, mas não ainda falar. E pensar aqui significaria algo como 'falar para si mesmo'. (p.32).

Temos neste caso uma alusão ao fato de que a linguagem do pensamento seria inata, visto que: (1) a criança já possuiria uma linguagem anterior a uma dada língua natural com que se depara; e (2) 
a criança pensaria mesmo sem falar, ou, nos termos de Augustine, falaria para si mesma, ao pensar. Uma linguagem privada.

Partindo para o funcionamento de cada uma dessas linguagens, se podemos assim dizer, diferenças entre a linguagem privada e a linguagem pública ainda são visualizadas. Tomando por base a linguagem pública, Fodor a concebe como regulada por convenções da comunidade do discurso. Neste caso, entrariam em cena intenções e crenças na escolha de um termo a partir de situações que são paradigmáticas para aquele termo. Enfim, para o autor, o uso da linguagem natural, de forma coerente, ocorre quando há uma certa correspondência entre aquilo em que se acredita e a forma das palavras que se usa para expressar crenças.

Por outro lado, de acordo com Fodor, a linguagem privada (ou do pensamento) estaria ligada à representação dos processos mentais. Assim, para cada atitude proposicional dos organismos (temer, querer, acreditar, intencionar, aprender, perceber) haveria uma operação computacional correspondente entre o organismo e alguma fórmula do código interno. Operação computacional está sendo tomada aqui, literalmente, como uma operação definida por uma fórmula (interna): Ter uma atitude $R$ para a proposição $P$ é contingente idêntico a estar em uma relação computacional C para a fórmula (ou seqüência de fórmulas) F. (p.77).

Fodor apresenta, assim, o seu argumento para a postulação de uma linguagem privada, apoiado em uma analogia entre, de um lado, a máquina e, de outro, modelos que não falariam a língua na qual eles computam. Ou seja, teríamos duas linguagens distintas.

A propósito, Pinker (2002), outro estudioso do campo da CC que também aborda a linguagem, compartilha dessa opinião de Fodor. Para Pinker, os pensamentos abarcariam grande quantidade de informação, mas quando vamos comunicá-los a alguém (por questões de tempo e curto período de atenção do ouvinte), estes se resumiriam a poucas sentenças (cabendo ao ouvinte inferir o restante). Pinker conclui, então, que as pessoas falariam numa língua do pensamento (o mentalês). Para o autor, talvez ela se pareça um pouco com cada um dos idiomas falados; no entanto, comparado com qualquer outra língua, o mentalês deve ser mais simples num sentido (não existiriam palavras e construções dependentes do contexto, informações sobre pronúncia das palavras e sua ordem) e mais rico num outro (vários símbolos conceituais deveriam corresponder a uma determinada palavra no idioma falado, deveria haver uma maneira para diferenciar conceitos logicamente distintos e para ligar símbolos diferentes que se referem a uma mesma coisa). Mas, para que essas línguas sirvam ao pensamento de modo adequado, seria importante que tivessem mais coisas em comum entre si do que em relação aos correspondentes falados; acredita-se, pois, em um mentalês universal (logo, as línguas do pensamento não seriam diferentes umas das outras). Portanto, parece-nos que, para Pinker, o mentalês supriria todas as carências da língua falada e se apresentaria como a melhor maneira de representar o pensamento. Além disso, assim como Fodor, Pinker defende a existência de duas línguas, prevalecendo a eficácia da língua do pensamento na articulação de processos mentais.

Em suma, de acordo com o que foi por nós colocado, para Fodor, todo organismo possuiria, então, dois tipos de linguagem: (1) a natural ou pública, que o falante saberia e pela qual faria sua aderência às convenções (meio de comunicar atitudes proposicionais - crenças e formas de palavras que expressam essa atitude) que regulam a linguagem; e (2) a privada, pela qual o falante processaria as computações que fundamentam seus comportamentos (meio para as computações básicas dos processos cognitivos).

As atitudes proposicionais de um organismo, há pouco citadas, são para Fodor contingentes aos processamentos de dados - ou seja, seqüências de operações sobre fórmulas da linguagem interna (do pensamento). Para Fodor, essa linguagem do pensamento ou privada estaria disponível para o uso como veículo dos processos cognitivos. Ao contrário do que muitas linhas do estudo do pensamento defendem, de acordo com Fodor, os organismos não teriam apenas linguagens naturais, mas também uma linguagem privada, por meio da qual eles conduziriam as computações que 
fundamentam seus comportamentos. Segundo o autor, quando uma pessoa compreende uma sentença, há um processo análogo ao que acontece quando a máquina compreende (uma sentença em sua linguagem de computação). Fodor faz essa analogia com a máquina provando que há modelos que não falam a linguagem em que eles computam. Com esse argumento, o autor pretende fornecer um modelo potencial empírico para estabelecer a relação entre linguagem natural e linguagem do pensamento.

Finalmente, em relação aos dois tipos de linguagem, Fodor assume que:

* aprender uma linguagem natural é aprender as regras que determinam as extensões de seus significados;

* a língua interna tem que ser rica o suficiente para explicar qualquer predicado de uma linguagem natural que pode ser aprendida;

* há certos pensamentos que não se poderia pensar pelo fato de que não se aprendeu uma linguagem;

* não há nada que possa ser expresso em linguagem natural que não possa ser expresso em linguagem do pensamento.

\section{NEUROLINGÜÍSTICA: "MÚLTIPLAS LINGUAGENS"}

Como vimos, Fodor faz uma distinção entre linguagem pública e linguagem privada. Vejamos o que uma neurolingüística discursivamente orientada poderia dizer a respeito dessa distinção. Segundo Morato (1997), Humboldt é quem introduz o domínio da linguagem (não da semiose) no pensamento humano: "Historicamente nós não encontramos o homem no mundo a não ser falando" (apud. MORATO, 1997, p.123). Ao fazer essa introdução, Humboldt apresenta um conjunto de propriedades do sentido da linguagem que impõem uma natureza que se poderia entender como enunciativa à relação entre linguagem e cognição. Com base em Morato (1998), poderíamos, pois, dizer que, para Humboldt, assim como para Vygotsky (1987), a significação é o que plasma linguagem e pensamento. Ainda segundo Morato, o que torna possível a ligação entre Vygotsky e Humboldt (e mesmo Bakhtin) é o fato de que todos entendem a linguagem não como um código, mas como trabalho/atividade. Desse modo, a atividade mental seria ela própria enunciativa; conseqüentemente, a língua não seria simplesmente um intermediário entre nosso pensamento e o mundo. Na realidade, não há possibilidades de pensamento ou de conteúdos cognitivos fora da linguagem nem possibilidades de linguagem fora de processos interativos humanos. Em resumo, se o discurso é fundador do sentido, para uma neurolingüística discursivamente orientada, importa ainda o fato de que ele também intervém na relação entre linguagem e cognição.

Ao contrário do que é postulado por Fodor, se levarmos em conta as considerações de Morato (1998), não seria possível estabelecer com tanta clareza uma distinção entre linguagem pública (natural) e linguagem privada (do pensamento). Para Fodor, o que pode ser entendido enquanto suporte para o pensamento seria o que ele define como linguagem privada. Ao contrário, para a neurolingüística, é justamente o discurso (ou seja, o que Fodor talvez chamasse de linguagem pública) que intervém na relação cognição/linguagem.

Na perspectiva da neurolingüística, não haveria, portanto, a necessidade de fórmulas no código interno, dadas de maneira inata, já que não há possibilidade de pensamento fora da linguagem. Além

${ }^{3} \mathrm{O}$ título acima faz alusão ao fato de que as teorias de orientação discursiva, como é o caso da corrente neurolingüística que assumiremos a seguir, entendem a linguagem como múltipla, contraditória, atravessada por várias vozes (o Outro), por discursos que antecederam o atual, bem como pela história, cultura e subjetividade. 
disso, ao contrário do que defende Fodor, essa linguagem é aquela que utilizamos para comunicar, convencer, persuadir, dominar - aquela sobre a qual não temos controle e que é atravessada pela história, pela cultura e pela subjetividade (aspectos que Fodor não vê como vinculados à linguagem). Portanto, o que Fodor entende como linguagem pública ou natural teria vínculo direto com o pensamento, sem que haja a necessidade de um segundo "sistema", composto por fórmulas e precisão matemática, para essa função.

Morato (1997) nos possibilita, ainda, compreender com mais clareza as idéias de Fodor. Segundo a autora, as vertentes lingüísticas que consideram a significação como o ponto de vista fundamental sobre a linguagem, entendem que esta não é apenas signo. Retomando Humboldt, a autora defende que a linguagem é um trabalho do pensamento que justamente ganha forma pela atividade constitutiva da linguagem. Partindo dessa perspectiva enunciativa que coloca a linguagem e a cognição em relação, podemos entender que a construção do sentido não se dá de maneira totalmente subjetivada, ou seja, controlada pelo indivíduo e seu cérebro, alheia à história e ao valor intersubjetivo da linguagem.

Logo, se tomarmos por base a noção de Fodor de linguagem natural (pública), vemos que o autor acaba por reduzi-la a um veículo para a comunicação verbal, entendida (esta última) como um mero processo de codificação/decodificação. Tais processos, para Fodor, aconteceriam nos cérebros do falante e do ouvinte, tendo estes total controle da situação comunicativa, desde que haja um código (idioma) comum entre eles. Portanto, para que exista "sucesso" na transmissão de uma "mensagem" bastaria que esta fosse compreendida por ambos (falante/ouvinte) e que obedecesse a uma condição de verdade (Fred é um filósofo se Fred for realmente um filósofo). Morato (1998), por sua vez, vai de encontro a essas idéias; e para melhor sedimentar o pressuposto de que a linguagem não é apenas um veículo externo, responsável pelo intercâmbio social, cita Humboldt: “(a linguagem) é fator indispensável ao desenvolvimento do poder intelectual e para que tenha acesso a uma visão de mundo" (apud MORATO, 1998, p. 86).

Para Morato (2001), portanto, a tarefa de significar e compreender o real (concurso da linguagem, acesso ao mundo que nos apresenta) envolve inúmeros fatores, Dentre os quais podemos destacar as propriedades da língua, da cognição e do inconsciente, além da qualidade das interações humanas, das condições materiais e das contingências culturais e ideológicas da vida em sociedade. A autora menciona, ainda, a importância dos universos discursivos que orientam nossa ação no mundo, os diferentes contextos lingüístico cognitivos nos quais as significações são produzidas e as normas pragmáticas que regem o uso da linguagem. Fodor não toca nessas questões, apenas aborda brevemente o fato de que, algumas vezes, não temos controle sobre aquilo que dizemos - questão crucial e intensamente debatida pelas teorias de cunho discursivo.

\section{REFERÊNCIAS BIBLIOGRÁFICAS}

FODOR, J. (1975). The language of thought. Cambridge (Massachussetts): Harvard University Press. (2000). The mind doesn't work that way: The scope and limits of Computacional Psychology. Cambridge: The MIT Press.

GARDNER, H. (1996). A nova ciência da mente: Uma história da revolução cognitiva. São Paulo: EDUSP.

MORATO, E. M. (1997). Discurso e neurolingüística: problemas e perspectivas. Cadernos da FFC. Marília, v.6, n.2.

(1998). A contribuição de Vygotsky para a pesquisa hoje: As relações entre Linguagem e Cognição e sua repercussão para a pesquisa lingüística. In: Centenário de nascimento de Piaget, Freinet, Vygotsky, Jakobson. Campinas: Faculdade de Educação da Unicamp. 
(2001). Neurolingüística. In: MUSSALIM, F. \& BENTES, A. C. (orgs.) Introdução à lingüística: domínios e fronteiras - v. II. São Paulo: Cortez.

SAUSSURE, F. de. (1995). Curso de lingüística geral. 20ed. São Paulo: Cultrix.

SEARLE, J.R. (1980). Minds, Brains and Programs. In: The behavioral and brain science. Cambridge: Cambridge University Press; pp 417-424.

VYGOTSKI, L.S. (1987). Linguagem e pensamento. São Paulo: Martins Fontes.

\section{BIBLIOGRAFIA COMPLEMENTAR}

CHOMSKY, N. (1957). Syntatic structures. The Hague: Mountoun.

(1972). Language and mind. 2ed. Nova York: Harcourt Brace Javanovich.

COUDRY, M. I. H. (1988). Diário de Narciso: discurso e afasia. 2ed. São Paulo: Martins Fontes.

DUPUY, J.P. (1996). Nas origens das ciências cognitivas. São Paulo: EDUSP.

EYSENK, M.W. (1992). Psicologia cognitiva: um manual introdutório. Porto Alegre: Artes Médicas.

SOARES, A. B. (1993). O que são Ciências Cognitivas. 1ed. São Paulo: Brasiliense.

THAGARD, P. (1998). Mente: Uma Introdução à Ciência Cognitiva. Porto Alegre: Artes Médicas. 